\title{
When is Situation Semantics Allowed?
}

\author{
Paul Elbourne \\ Massachusetts Institute of Technology
}

\section{Introduction}

There is a reading of (1a) which can be paraphrased as in (1b). The standard account of this would attribute the covariation to his being interpreted as a bound individual variable, perhaps with the aid of a lambda-abstractor in the syntax as in (1c) (Heim and Kratzer 1998).

(1) a. Every man beats his donkey.

b. For all $x$ such that $x$ is a man, $x$ beats $x$ 's donkey.

c. every man $\lambda_{1}\left[\mathrm{t}_{1}\right.$ beats his ${ }_{1}$ donkey]

Quantification over individuals seems to be all we need to capture the covariation in (1a).

It has been proposed within the framework of situation semantics (Kratzer 1989) that there can also be quantification over situations. The most convincing case is that of quantificational adverbs (Berman 1987, Heim 1990, von Fintel 1994)_I will be assuming in this paper that the correct analysis of these will of ten involve treating them as quantifiers over situations, sometimes with an if-clause providing a restrictor. However, this raises the general question of when exactly we have quantification over situations. In particular, do normal quantifiers like every ever quantify over situations? If so, do every and the others always quantify over situations?

In the next section of this paper I will give two arguments that quantifiers like every must at least occasionally quantify over situations. Then I will turn my attention to the second question above and argue that there are some configurations in which they must not be allowed to do this. I should point out before we go any further, however, that this paper presupposes some sympathy with the project of explaining donkey sentences and similar instances of anaphora by means of $\mathrm{E}$ type pronouns and situation semantics (Heim 1990), and that proponents of DRT analyses will not be moved by the arguments in Section 2; there will, however, be a novel argument against DRT in Section 4.4. ${ }^{1}$

\section{Does every ever quantify over situations?}

\subsection{Sage plant sentences}

Heim (1990: 159-64) argues that in the analysis of (2) using the E-type analysis or its descendants, it is necessary to quantify over situation variables in addition to individual variables. 
Every woman who bought a sage plant here bought eight others along with it.

A straightforward E-type analysis would have it here mean "the unique sage plant bought by $x$ " (for every woman $x$ ), and runs into trouble because the meaning of the sentence makes it clear that there is no such unique sage plant for every woman - in fact, every woman bought nine sage plants.

The difficulty can be averted, however, if we neutralize this unwelcome uniqueness presupposition by relativizing it to small situations. In particular, let us assume (as in Elbourne 2001) that rules for quantifiers like every in situation semantics look like (3) (a simplification of the suggestion in Heim 1990).

$\llbracket\left[\begin{array}{lll}\text { every }_{\mathrm{s}_{1}} & \alpha]_{\mathrm{s}_{2}} & \beta\end{array}\right] \rrbracket^{\mathrm{g}}=$ True iff, for every pair of an individual $x$ and a minimal situation $\mathbf{s}_{1}$ such that $x \in \llbracket \alpha \rrbracket^{g \mathbf{s}_{1} \backslash \mathbf{s}_{1}}$, there is a situation $\mathbf{s}_{2}$ such that $\mathbf{s}_{1} \leq \mathbf{s}_{2}$ and $x \in \llbracket \beta \rrbracket^{g \mathbf{s}_{1} \mid \mathbf{s}_{1}, \mathbf{s}_{2} \backslash \mathbf{s}_{2}}$.

Situation variables will be part of the object language. Every predicate will have

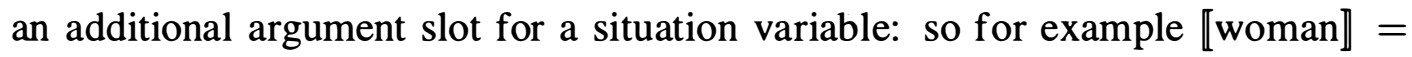
$[\lambda s . \lambda x . x$ is a woman in $s]$. Quantificational structures work by having all the situation variables in the restrictor be $s_{1}$ and at least some of the situation variables in the nuclear scope be $s_{2}$; there can also be situation variables $s_{1}$ in the nuclear scope, but no others. ${ }^{2}$

Applying (3) to (2) necessitates the (simplified) LF (4) ${ }^{3}$, where material struck through is deleted at PF, and produces the truth conditions in (5).

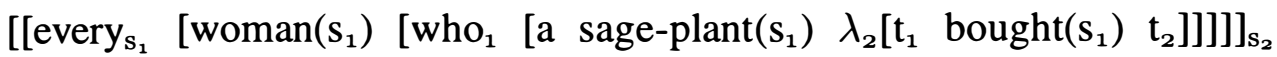
bought-eight-other-sage-plants $\left(\mathrm{s}_{2}\right)$ along with [it sage plant $\left.\left(\mathrm{s}_{1}\right)\right]$ ]]

For every pair of an individual $x$ and a minimal situation $\mathbf{s}_{1}$ such that $x$ is a woman in $\mathbf{s}_{1}$ and there is a $y$ such that $y$ is a sage plant in $\mathbf{s}_{1}$ and $x$ bought $y$ in $\mathbf{s}_{1}$, there is a situation $\mathbf{s}_{2}$ such that $\mathbf{s}_{1} \leq \mathbf{s}_{2}$ and $x$ bought eight other sage plants in $\mathbf{S}_{2}$ along with the unique $z$ such that $z$ is a sage plant in $\mathbf{s}_{1}$.

These truth conditions are intuitively correct. But to achieve them, every must quantify over situations.

\subsection{Strict and sloppy identity with donkey anaphora}

A previously unnoted argument in favor of every quantif ying over situations can be constructed on the basis of (6), which I have discussed elsewhere in another context (Elbourne 2001).

(6) Every man who owns a donkey beats the donkey.

Intuitively, this sentence has the same truth conditions as its more celebrated variant (7).

(7) Every man who owns a donkey beats it. 
We are now faced with the task of accounting for this reading. The fact that there is covariation implies binding of some kind. And we have two choices: individual variables or situation variables.

How, then, could we attempt to capture the meaning of (6) by means of bound individual variables? We must presumably add an individual variable somewhere in the definite description and have it bound by the subject QP. Just adding an individual variable is not going to be good enough, however, since every man who owns a donkey can only consistently bind variables that range over men who own donkeys; we do not want to end up with truth conditions like, "For all $x$ such that $x$ is a man who owns a donkey, $x$ beats the donkey (identical to) $x$." What we want is something more like, " $x$ beats the donkey owned by $x$." We are forced, then, to make some part of the definite description, plausibly the definite article, into something very similar to a Cooper-style donkey-pronoun (Cooper 1979). We add a variable $R$ that will be assigned as its value some contextually salient relation, in this case something like [ $\lambda x . \lambda y . y$ is owned by $x]$; the pro sister of $R$ will be bound by the (lambda-abstractor below the) subject, as we see in (8).

[every man who owns a donkey] $\lambda_{2}\left[\mathrm{t}_{2}\right.$ beats $\left[\left[\right.\right.$ the $\left.\left[R_{\langle 7,\langle\mathrm{e}, \mathrm{et}\rangle\rangle} \operatorname{pro}_{2}\right]\right]$ donkey]]

(I here follow the simplified version of Cooper 1979 suggested by Heim and Kratzer 1998.) We just need a revised lexical entry for the definite article (9), allowing it to deal with its covert Cooper-style restrictor as well as its overt NP argument, and then we are ready to go: we obtain the truth conditions in (10) for (6), via the LF (8).

$$
\lambda f_{\langle\mathrm{e}, \mathrm{t}\rangle} \cdot \lambda g_{\langle\mathrm{e}, \mathrm{t}\rangle}: \exists ! x(f(x)=1 \& g(x)=1) . \iota x(f(x)=1 \& g(x)=1)
$$

(10) For all $x$ such that $x$ is a man who owns donkey, $x$ beats the unique $y$ such that $y$ is owned by $x$ and $y$ is a donkey.

This is rather stipulative, of course, but it seems to do the job.

Unfortunately, there is a serious empirical objection to this line of attack, which, as far as I can see, would extend to any approach in which the definite description is converted into something bindable by the subject QP by means of an individual variable. That is that the VP ends up meaning something like ' $\lambda x . x$ beats the donkey owned by $x$ ' or ' $\lambda x . x$ beats the donkey of $x$ '. This is a problem because we then predict that a continuation sentence with a type e subject and VPellipsis (or a downstressed VP) will have a sloppy reading. We do not need to commit ourselves to any particular theory of VP-ellipsis in order to see this. We only have to observe that a sloppy reading is available in (11), where the VP spells out as closely as possible in words the VP-meaning we end up with for (6) under the analysis being considered.

(11) a. In this town, every farmer who owns a donkey beats the donkey he owns, and the priest does too.

(strict, sloppy)

b. In this town, every farmer who owns a donkey beats the donkey he owns, 
and the priest beats the donkey he owns too.

(strict, sloppy)

Whatever mechanism allows the sloppy reading in (11) would also allow one in (12), under the assumption that the overt VPs in (12) have the same meaning as the overt VPs in (11), which is the hypothesis under consideration. We do not in fact obtain sloppy readings in (12), however.

(12) a. In this town, every farmer who owns a donkey beats the donkey, and the priest does too. (strict, *sloppy)
(

b. In this town, every farmer who owns a donkey beats the donkey, and the priest beats the donkey too.

(strict, *sloppy)

These sentences only have a reading in which the priest beats the donkeys of the farmers. There is no reading in which the priest has a donkey and beats it. The analysis of (6) by means of bound individual variables makes a prediction that is straightforwardly wrong, therefore.

Let us now construct an analysis of (6) that relies on bound situation variables. We can use the rule for every that we saw above in (3). Applying (3) to (6), we end up with the LF (13) and the truth conditions (14).

(13) $\left[\left[\operatorname{every}_{s_{1}}\left[\operatorname{man}\left(s_{1}\right)\left[w o_{1}\left[\operatorname{adonkey}\left(s_{1}\right) \lambda_{2}\left[t_{1} \operatorname{owns}\left(s_{1}\right) t_{2}\right]\right]\right]\right]\right]_{s_{2}}\right.$ beats $\left(s_{2}\right)$ the $\left.\operatorname{donkey}\left(\mathrm{s}_{1}\right)\right]$

(14) For every pair of an individual $x$ and a minimal situation $\mathbf{s}_{1}$ such that $x$ is a man in $\mathbf{s}_{1}$ and there is a $y$ such that $y$ is a donkey in $\mathbf{s}_{1}$ and $x$ owns $y$ in $\mathbf{s}_{1}$, there is a situation $\mathbf{s}_{2}$ such that $\mathbf{s}_{1} \leq \mathbf{s}_{2}$ and $x$ beats in $\mathbf{s}_{2}$ the unique $z$ such that $z$ is a donkey in $\mathbf{s}_{\mathbf{1}}$.

Note how a covarying reading is achieved for the donkey solely by means of situation variables.

How does this deal with the obligatory strict reading in (12)? The right results would be achieved if we could have an LF in which every farmer who owns a donkey $\mathrm{QRs}$ out to bind into the second conjunct, as in (16) overleaf. For such LF violations of the Co-ordinate Structure Constraint, see Ruys 1993, where it is shown that the CSC can be violated by QPs in the first conjunct when there is a variable in the second that can be bound by them. For example, $(15 \mathrm{~b})$ has a reading in which every professor outscopes some student and binds him; contrast (15a), where, in the absence of a bindable variable in the second conjunct, every professor cannot have scope above some student.

(15) a. Some student likes every professor and hates the Dean.

b. Some student likes every professor and wants him to be on his committee.

In (16), analogously, I propose that the QP subject of the first conjunct can scope out, since the situation variables in the second conjunct can thus be bound - a natural extension of Ruys's generalization. Further evidence for the possibility of 
(16)

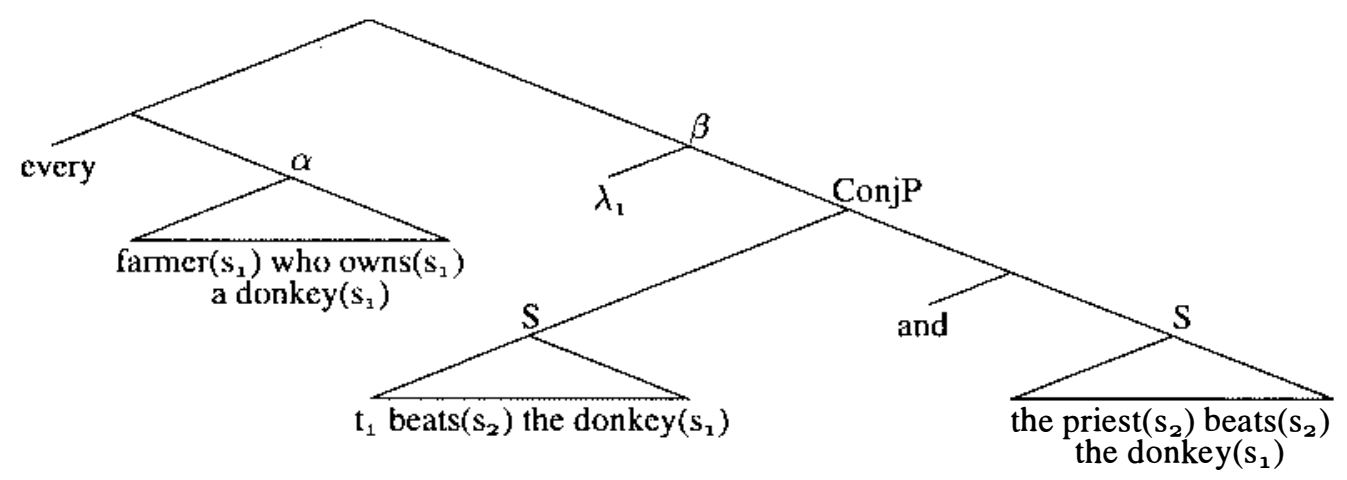

something like (16) comes from the variant of our sentence in (17).

(17) Every farmer who owns a donkey beats the donkey, and his wife does too.

Here, every farmer... binds his, which means it must be binding into the second conjunct. 4

Given (16), then, we can apply our rule (3) and obtain the truth conditions in (18).

(18) For every pair of an individual $x$ and a minimal situation $\mathbf{s}_{1}$ such that $x$ is a farmer in $\mathbf{s}_{1}$ and there is a $y$ such that $y$ is a donkey in $\mathbf{s}_{1}$ and $x$ owns $y$ in $\mathbf{s}_{1}$, there is a situation $\mathbf{S}_{2}$ such that $\mathbf{S}_{1} \leq \mathbf{S}_{2}$ and $x$ beats in $\mathbf{S}_{2}$ the unique $z$ such that $z$ is a donkey in $\mathbf{s}_{1}$ and the unique $u$ such that $u$ is a priest in $\mathbf{S}_{2}$ beats in $\mathbf{S}_{2}$ the unique $v$ such that $v$ is a donkey in $\mathbf{s}_{1}$.

The correct strict reading is obtained, and there is no evident way to produce a sloppy reading in this system, in accordance with the data. The covariance is achieved in (16) by the situation variable $\mathrm{s}_{1}$ on the donkey being bound. The only other possibility for the identity of the situation variable on the donkey, given the way we have set up the system, is $s_{2}$ - we are in the nuclear scope of a quantificational structure, so only $s_{1}$ and $s_{2}$ are allowed. If we had $s_{2}$ on the donkey in (16), would the right results still be obtained? Yes, because the situations $s_{2}$ are extensions of the situations $s_{1}$. The unique donkey in each situation $s_{2}$ must be the unique donkey in each corresponding situation $\mathrm{s}_{1}$, since we have already set up the situations $s_{1}$ to contain exactly one donkey each and the situations $s_{1}$ are part of the situations $s_{2}$. (If we added another donkey in $s_{2}$ that was not in $s_{1}$, one belonging to the priest, say, there would no longer be a unique donkey in $\mathrm{s}_{2}$.) Whichever way we do things, then, the priest ends up beating the donkeys of the situations $\mathrm{s}_{1}$, the donkeys of the farmers, as desired.

The right results are obtained, therefore, provided we allow quantifiers like every to quantify over situations. 


\section{Does every always quantify over situations?}

Given that we must allow ordinary quantifiers to quantify over situations some of the time, we must now ask whether there is any reason to say that they ever do not. Even simple cases that do not involve donkey anaphora can, after all, be analyzed by means of situation semantics rules for quantifiers. I repeat (1a) and (3) as (19) and (20). Applying (20) to (19) gives us the truth conditions in (21), which are intuitively correct.

(19) Every man beats his donkey.

(20) $\llbracket\left[\left[\text { every }_{\mathrm{s}_{1}} \alpha\right]_{\mathrm{s}_{2}} \beta\right] \rrbracket^{\mathrm{g}}=$ True iff, for every pair of an individual $x$ and a minimal situation $\mathbf{s}_{1}$ such that $x \in \llbracket \alpha \rrbracket^{\mathrm{g} \mathbf{s}_{1} \backslash \mathbf{s}_{1}}$, there is a situation $\mathbf{s}_{2}$ such that $\mathbf{s}_{1} \leq \mathbf{s}_{2}$ and $x \in \llbracket \beta \rrbracket^{g \mathbf{s}_{1} \backslash \mathbf{s}_{1}, \mathbf{s}_{2} \backslash \mathbf{s}_{2}}$.

(21) For every pair of an individual $x$ and a minimal situation $\mathbf{s}_{1}$ such that $x$ is a man in $\mathbf{s}_{1}$, there is a situation $\mathbf{s}_{2}$ such that $\mathbf{s}_{1} \leq \mathbf{s}_{2}$ and $x$ beats in $\mathbf{s}_{2}$ the unique $z$ such that $z$ is $x$ 's donkey in $\mathbf{s}_{\mathbf{2}}$.

Having once admitted the outré possibility of (20), can we ever exclude it?

There are two conceivable positions which seem worth investigating:

- Modest Situation Semantics: Quantifiers are systematically ambiguous between versions quantifying only over individual variables and versions like (20). When there is no need for the situation versions (in some sense to be made precise), the individual-only versions have to be used.

- Shameless Situation Semantics: Quantifiers always quantify over situations, as in (20).

Modest Situation Semantics, as I conceive it, would not allow the situation semantics version of every to be used in (19), since the version which quantifies only over individuals would do just fine. Shameless Situation Semantics, by definition, would apply (20) to simple sentences like (19).

Assuming that situation variables are part of object language representations, as Heim 1990 proposed, another question should be raised. If Modest Situation Semantics is correct, do situation variables vanish when they are not being quantified over (which would mean that predicates are systematically ambiguous between versions taking situation arguments and versions that do not), or do they stick around unbound and refer to large contextually salient situations in which all the quantificational action (over individuals) takes place?

I will not attempt to answer this second question in this paper. I will be examining the two rival hypotheses, Modest Situation Semantics and Shameless Situation Semantics. The data which will bear on the choice between them concerns the behavior of the Japanese pronouns kare 'he' and kanozyo 'she'; the relevant phenomena will be seen to constitute an argument for Modest Situation Semantics. 


\section{Japanese kare and kanozyo}

\subsection{The basic data}

Japanese kare 'he' and kanozyo 'she' can be referential but not bound (Noguchi 1997 and much previous literature), as we see in the following examples.

Although I am not aware that this has been noted before in the literature, there seem to be two dialects of Japanese, as far as these words are concerned. The first places no restrictions on where kare and kanozyo may be placed with respect to coreferential terms; it is exemplified in (22) and (23).

a. John ${ }_{i}$-ga [kare ${ }_{i}$-ga atama-ga ii to] omotte-iru John-NOM he-NOM head-NOM good COMP think-PRES ' $\mathrm{John}_{i}$ thinks that he ${ }_{i}$ is intelligent.'

b. Mary ${ }_{i}$-ga [ kanozyo $_{i}$-ga atama-ga ii to] omotte-iru Mary-NOM she-NOM head-NOM good COMP think-PRES 'Mary thinks that she $_{i}$ is intelligent.'

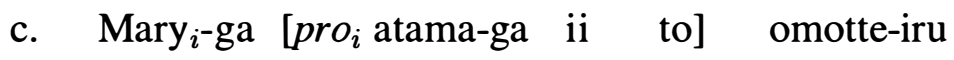
Mary-NOM head-NOM good COMP think-PRES 'Mary thinks that she $_{i}$ is intelligent.' everyone-NOM he-NOM head-NOM good COMP think-PRES 'Everyone ${ }_{i}$ thinks that he ${ }_{i}$ is intelligent.'
a. *Daremo ${ }_{i}$-ga [ $\mathrm{kare}_{i}$-ga atama-ga ii to] omotte-iru
b. *Daremo-ga [kanozyo $_{i}$-ga atama-ga ii to] omotte-iru everyone-NOM she-NOM head-NOM good COMP think-PRES 'Everyone ${ }_{i}$ thinks that she ${ }_{i}$ is intelligent.'
c. Daremo-ga [pro $_{i}$ atama-ga ii to] omotte-iru everyone-NOM head-NOM good COMP think-PRES 'Everyone ${ }_{i}$ thinks they' ${ }_{i}$ 're intelligent.'

Note that (23a) and (23b) are bad on the reading where the pronouns are interpreted as bound. 5

The second dialect consists of speakers who also find (22a) and (22b) ungrammatical, in addition to (23a) and (23b). When the pronouns are more deeply embedded, however, exactly the same pattern emerges with respect to the grammaticality of bound and referential readings, as we see in (24) and (25).
a. John $_{i}$-ga kare $_{i}$-no musume-no atarasii syasin-o motteiru John-NOM he-GEN daughter-GEN new photo-ACC has 'John ${ }_{i}$ has a new photo of his ${ }_{i}$ daughter.'
b. Mary ${ }_{i}$-ga kanozyo $_{i}$-no musume-no atarasii syasin-o motteiru Mary-NOM she-GEN daughter-GEN new photo-ACC has 'Mary ${ }_{i}$ has a new photo of her $i$ daughter.'


a. *Dono titioya-mo kare $_{i}$-no musume-no atarasii syasin-o motteiru which father-even he-GEN daughter-GEN new photo-ACC has 'Every father ${ }_{i}$ has a new photo of his ${ }_{i}$ daughter.'

b. *Dono hahaoya-mo kanozyo $_{i}$-no musume-no atarasii which mother-even she-GEN daughter-GEN new syasin-o motteiru photo-ACC has

'Every mother $_{i}$ has a new photo of her ${ }_{i}$ daughter.'

I do not know why there should be the dialectal difference, or exactly what is going on in the second dialect to make (22a) and (22b) ungrammatical. I will leave these questions aside, however, since the second dialect clearly maintains the basic pattern found in the first one: kare and kanozyo cannot be bound, even though minimally different sentences where they corefer with a type e lexical item in the place of the QP in the bad sentences are fine.

\subsection{Previous accounts}

The bulk of my review and criticism of previous accounts of kare and kanozyo is based on the review carried out in Noguchi 1997, to which readers are referred for more details.

Some syntactic treatments of these facts amount only to restatements of the problem. I would include here Katada's (1991) proposal that kare must be operatorfree and Aoun and Hornstein's (1992: 5) proposal that, "Kare must be A'-free." These statements may well be true, but from them we have learned nothing about the nature of kare; we are left wondering what about it is such that it has to be operator-free or $\mathrm{A}^{\prime}$-free. The same can be said about Montalbetti's treatment of kare (Montalbetti 1984: 187), which was to state that, "Overt pronouns cannot have formal variables as antecedents." A formal variable (the term is Higginbotham's) is a trace left by a QR'd QP or wh-operator. Again, this is just a restatement of the problem.

Huang (1991) suggested that kare and kanozyo cannot be bound because of competition from the reflexive pronoun: when the reflexive pronoun is possible, kare and kanozyo will not be possible. But, as Noguchi points out (1997: 774-5), the reflexive pronoun zibun is subject-oriented, and therefore cannot be used, for example, with a dative antecedent:

a. Mary-ga John ${ }_{i}$-ni [ kare $_{i}$-ga tensai-da to] it-ta

Mary-NOM John-DAT he-NOM genius-COP COMP say-PAST

'Mary told $\mathrm{John}_{i}$ he $_{i}$ was a genius.'

b. *Mary-ga $\mathrm{John}_{i}$-ni [zibun ${ }_{i}$-ga tensai-da to] it-ta

Mary-NOM John-DAT self-NOM genius-COP COMP say-PAST

'Mary told $\mathrm{John}_{i}$ he $_{i}$ was a genius.'

Since zibun cannot be used in this configuration, it cannot provide competition for kare. So on Huang's account, we predict the following to be good (Noguchi 1997: 
774-5):

*Mary-ga dono hito $_{i}$-ni-mo [ kare $_{i}$-ga tensai-da to $]$ it-ta Mary-NOM which person-DAT-even he-NOM genius-COP COMP say-PAST

'Mary told every person ${ }_{i}$ he $_{i}$ was a genius.'

The example is bad, however, mèaning that Huang's account cannot be correct. ${ }^{6}$

Hoji (1991) advances the puzzling proposal that kare cannot be bound because it is a demonstrative. He does not take account of the many examples which show that demonstratives can in fact be bound. An example is (28), where no senator raises at LF and binds that senator.

Mary talked to no senator before that senator was lobbied.

More would need to be said to make this a viable explanation. ${ }^{7}$

Noguchi (1997: 777) says that kare and kanozyo are nouns, citing the evidence in (29)-(31).

a. tiisai kare

b. sinsetuna kanozyo

kind she

a. watasi-no kare

I-GEN he

'my boyfriend'

b. anato-no kanozyo

you-GEN she

'your girlfriend'

a. kono kare

this he

'this male person'

b. ano kanozyo

that she

'that female person'

If something can be modified by an adjective (29) or a determiner (31) and sometimes mean 'boyfriend' (30), Noguchi says, we have good reason to believe that it is a noun. He further maintains the following two theses: nouns cannot be functional items; and, "Binding applies only to functional items" (1997: 783). Thus is explained the inability of our words to be bound.

However, this is open to challenge on three counts. First, it is in fact dubious to say that kare and kanozyo are nouns, or at least nouns in any normal sense of the word. To start with, my informants tell me that, for example, tiisai kare (which Noguchi does not translate into grammatical English) means something like 
'he, who is small'. It has the flavor, then, of a normal pronoun being modified by a non-restrictive relative clause, and is thus not evidence for kare being a noun at all. $^{8}$ As for the alleged ability of our words to be the arguments of determiners, this seems to be highly restricted: no native speaker I have consulted allows subete-no ('all') kare or futari-no ('two') kare, and judgments differ sharply about dono karega ('which...') and dono kare-mo ('every...'). Furthermore, Japanese nouns can quite generally be used with no overt determiner and receive an indefinite interpretation ('an N'); but this is completely impossible with kare. Rather than say that they are nouns, then, it seems more plausible to say that kare and kanozyo are basically pronouns which can be coerced into behaving like nouns in an idiosyncratic fashion, as in English locutions like the real me and Is it a he or a she?. Secondly, even if our words were nouns, it is simply arbitrary to assert, as Noguchi does, that nouns cannot be functional items. The lexical-functional distinction is left vague, and Noguchi needs to provide a principled account of it that clearly puts all nouns on the lexical side, even nouns which are used as pronouns and which thus seem rather 'functional'. Thirdly, since binding does not apply to all functional items (e.g. not to auxiliaries or complementizers!), we still have to appeal to properties of individual functional items to determine whether or not they can be bound. So the appeal to the lexical-functional distinction looks as if it would end up being irrelevant anyway - the individual properties in question, which only some functional items possess, could very well account for the differences in bindability between words without any mention of the lexical-functional distinction being made. I am far from being convinced, then, by the account of Noguchi.

\subsection{A new account}

I present here an outline of a new account, sufficient for the theoretical purposes that are my main concern in this paper.

My basic proposal is the following. There is one type of expression in the standard logical languages we use which could be referential, could be applied to many people indiscriminately like a pronoun, and yet would not be capable of being bound, and that is a bland definite description. I suppose, then, that $\llbracket$ kare $\rrbracket=$ $\iota x$ male $(x)$, and $\llbracket \operatorname{kanozyo} \rrbracket=\iota x$ female $(x) .^{9}$

It might be tempting to object to this idea by pointing out that some definite descriptions in natural language can be bound, as we have seen in (28), and as some speakers find in (32).

Mary talked to no senator before the senator was lobbied.

But such an objection would be misguided. My proposal is not that kare and kanozyo have the same semantics as, say, English the male person and the female person, but that they mean just something like ' $\iota x$ male $(x)$ ' and ' $\iota x$ female $(x)$ '. These latter expressions cannot be bound, because there are no free variables in them. Those natural language definite descriptions that can be bound cannot have meanings like ' $\iota x$ male $(x)$ '. There must also be a (locally) free individual variable 
that can be bound - in logical terms, something like ' $\iota x($ male $(x) \& x=y)$ '. (See Elbourne forthcoming for an argument about how best this is to be achieved.)

It might also be objected that I have not shown that it should not be possible to add an index to our words, so as to make them bindable. But the burden of proof, in my opinion, is firmly with those who would maintain that it should be possible to do this. There is no reason, on general grounds, to suppose that every expression of type e can be modified (somehow - the process is seldom given a fully explicit syntax and semantics ${ }^{10}$ ) with an index so as to make it bindable. It seems more likely that being able to host indices is a particular, lexically-specified property of some items, perhaps just pronouns (of the normal, non-kare sort) and traces. Some empirical evidence: many English speakers find (32) ungrammatical, despite being able to get bound variable readings quite easily with pronouns; so for some people it is impossible to add an index (whatever this means) to definite descriptions like the senator. There is also, as far as I know, no compelling reason to believe that proper names can bear indices. ${ }^{11}$ There is no more reason to believe that kare and kanozyo should be able to bear indices.

This account, combined with some claims I made earlier, makes a prediction. If I am right to say that kare and kanozyo are bland definite descriptions containing no bindable individual variables, and that donkey-anaphoric definite descriptions, as in (6), covary by means of situation variables, not individual variables, then kare and kanozyo should have E-type uses. I do not know of anywhere in the previous literature on these words where this prediction has been tested. But it turns out to be correct, as we see in the following examples. The sentences in (33) are acceptable only to the speakers of the first dialect mentioned above, the one that allows (22a) and (22b). Those in (34) are acceptable to all.

a. Musuko-ga iru dono hito-mo [kare-ga atama-ga ii to] son-NOM exists which person-even he-NOM head-NOM good COMP omotte-iru

think-PRES

'Every person who has a son thinks he's intelligent.'

b. Musume-ga iru dono hito-mo [kanozyo-ga atama-ga daughter-NOM exists which person-even she-NOM head-NOM ii to] omotte-iru good COMP think-PRES

'Every person who has a daughter thinks she's intelligent.'

a. Musuko-ga iru dono hito-mo kare-no atarasii syasin-o son-NOM exists which person-even he-GEN new photo-ACC motteiru has-PRES

'Every person who has a son has a new photo of him.' 
b. Musume-ga iru dono hito-mo kanozyo-no atarasii daughter-NOM exists which person-even she-GEN new syasin-o motteiru photo-ACC has-PRES

'Every person who has a daughter has a new photo of her.'

The truth conditions of (33a), for example, come out by means of our rule (20) to be those in (35).

(35) For every pair of an individual $x$ and a minimal situation $\mathbf{s}_{1}$ such that $x$ is a person in $\mathbf{s}_{1}$ and there is a $y$ such that $y$ is a son in $\mathbf{s}_{\mathbf{1}}$ and $x$ has $y$ in $\mathbf{s}_{\mathbf{1}}$, there is a situation $\mathbf{s}_{2}$ such that $\mathbf{s}_{1} \leq \mathbf{s}_{2}$ and $x$ thinks-intelligent in $\mathbf{s}_{2}$ the unique $z$ such that $z$ is male in $\mathbf{s}_{1}$.

There is only one difficulty, namely the mention of a unique male in the situations $\mathbf{s}_{1}$ (to mean the son), when the person whose son it is, who is also in $\mathbf{s}_{1}$, might also be male. But this difficulty, I think, is easily solved. It has been recognized for a while that the felicitous use of definite descriptions often requires clues from the context to justify the uniqueness conditions associated with them on both Russellian and Fregean accounts; we can after all talk about the table even though we know there is more than one table in the world. If speaker and hearer manage to arrive at some sufficiently similar narrowing down of the domain of discourse, such that within this restricted domain there is only one table, successful communication will take place. I suggest that essentially the same thing can happen with respect to situations. When faced with (35), and a context in which males are not excluded from being the people with sons, the hearer seeks to find some way to make sense of the uniqueness presupposition by evaluating the definite description with respect to homogeneous sub-parts of the situations $\mathbf{s}_{1}$. Natural sub-parts to choose would be those which include the son but exclude the parent. Why? Well, the sentence cannot mean that each person who has a son thinks him- or herself intelligent, because that would require a reflexive pronoun. When this impossible option is removed from consideration, there is indeed a unique male in each of the situations $\mathbf{s}_{1}$, namely the son, who is thus picked out with the bland definite description kare. ${ }^{12}$

\subsection{Excursus - a problem for DRT}

DRT accounts of donkey anaphora maintain that it is accomplished via unselective binding of individual variables. (See van Eijck and Kamp 1997 for a recent survey.) Kare and kanozyo, however, can be donkey pronouns but cannot be, or incorporate, bound individual variables. This is a counterexample to one of the most basic claims of DRT.

\subsection{A residual problem}

There is, however, a problem remaining for the current approach. If quantifiers can quantify over situations, in the way that has been previously suggested, how is it 
that they cannot do so in the sentences like (23a) and (23b), where no covarying reading is available for kare and kanozyo?

That is to say, given rules like (36), we seem to be predicting that (37) (repeated from (23a)) should have the truth conditions in (38).

$\left.\llbracket\left[\begin{array}{lll}\text { every }_{\mathrm{s}_{1}} & \alpha\end{array}\right]_{\mathrm{S}_{2}} \beta\right] \rrbracket^{\mathrm{g}}=$ True iff, for every pair of an individual $x$ and a minimal situation $\mathbf{s}_{1}$ such that $x \in \llbracket \alpha \rrbracket^{\mathrm{g} \mathbf{s}_{1} \backslash \mathbf{s}_{1}}$, there is a situation $\mathbf{s}_{2}$ such that $\mathbf{s}_{\mathbf{1}} \leq \mathbf{s}_{\mathbf{2}}$ and $x \in \llbracket \beta \rrbracket^{g \mathbf{s}_{1} \backslash \mathbf{s}_{1}, \mathbf{s}_{2} \backslash \mathbf{s}_{2}}$.

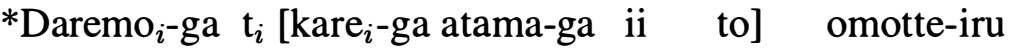 everyone-NOM he-NOM head-NOM good COMP think-PRES 'Everyone ${ }_{i}$ thinks that he ${ }_{i}$ is intelligent.'

(38) For every pair of an individual $x$ and a minimal situation $\mathbf{s}_{1}$ such that $x$ is a person in $\mathbf{S}_{1}$, there is a situation $\mathbf{S}_{2}$ such that $\mathbf{S}_{1} \leq \mathbf{S}_{2}$ and $x$ thinks in $\mathbf{S}_{2}$ that the unique $y$ such that $y$ is a male person in $\mathbf{s}_{\mathbf{1}}$ is intelligent.

(38), of course, is equivalent to "For all $x, x$ thinks $x$ is intelligent", which is precisely the reading (37) lacks.

\section{In praise of modesty}

Roughly speaking, it looks like we need to prevent quantification over situations in configurations where individual variables could be bound, as in (37), but allow it in donkey anaphora configurations, like those in (33) and (34). This looks like a job for Modest Situation Semantics.

Recall our two rival hypotheses from long ago (Section 3, to be precise):

- Modest Situation Semantics: Quantifiers are systematically ambiguous between versions quantifying only over individual variables and versions like (36). When there is no need for the situation versions (in some sense to be made precise), the individual-only versions have to be used.

- Shameless Situation Semantics: Quantifiers always quantify over situations, as in (36).

Shameless Situation Semantics cannot be of any help to us. It says that every always quantifies over situations, and hence incorrectly predicts (37) to be good with the reading (38).

Modest Situation Semantics, on the other hand, can spell out 'no need' in the above definition with the following principle.

Economy in Quantification

No use of the situation semantics variants of quantifiers is permitted when an indistinguishable interpretation is yielded by replacing the situation semantics quantifier with the corresponding individual-only quantifier and any DPs covalued with the trace of the QP with individual variables bound by the QP. 
(I assume that a QP will always have moved, either by QR or from a VP-internal subject position; if this turns out not to be the case in the ordinary run of things, the instructions for constructing the comparison LF could easily be amended so as to enforce it.) This principle, which is modelled closely on Reinhart's Rule I (Reinhart 1983, Grodzinsky and Reinhart 1993, Heim 1993, Reinhart 1997), is arguably an economy condition on semantic operations: rules like (36) quantify over both individuals and situations, and it is in an obvious sense more economical to quantify just over individuals. (39) is thus to be compared to Fox's (2000) economy conditions on LF operations like Quantifier Raising. ${ }^{13}$

To evaluate the use of the situation semantics quantifier in (37), which leads to the production of the unavailable truth conditions in (38), Economy in Quantification thus instructs us to construct the following minimally different $\operatorname{LF}(=(23 \mathrm{c})$ ), where it is to be understood that the individual-only version of the quantifier is used.

$$
\begin{aligned}
& \text { Daremo-ga } \mathrm{t}_{i}\left[\text { pro }_{i}\right. \text { atama-ga ii to] omotte-iru } \\
& \text { everyone-NOM head-NOM good COMP think-PRES }
\end{aligned}
$$

Kare in (37) is covalued with the trace of the QP: the trace of the QP in (37) contributes to (38) the $x$ in " $x$ thinks"; kare, meanwhile, ends up meaning "the unique $y$ such that $y$ is a male person in $\mathbf{s}_{1}$ ", which must be identical, for each $\mathbf{s}_{1}$, to $x$. Therefore in (40) kare is replaced by an individual variable pro bound by the QP. The truth conditions yielded by the LF (40) are just "For all $x$ such that $x$ is a person, $x$ thinks $x$ is intelligent." They are identical to those described in (38). So by (39) the situation semantics quantifier in (37) is not allowed - we have to use the individual-only version of daremo. But kare contains no bindable individual variable. So we correctly arrive at the conclusion that there is no way to get a covarying interpretation for kare in this example.

Now let us evaluate the use of the situation semantics quantifier in a donkey anaphora example like (33a), repeated here as (41) with its truth conditions (35) repeated as (42).

(41) Musuko-ga iru dono hito-mo ${ }_{i}$ t $\mathrm{t}_{i}$ [kare-ga atama-ga ii to] son-NOM exists which person-even he-NOM head-NOM good COMP omotte-iru

- $\quad$ think-PRES

'Every person who has a son thinks he's intelligent.'

(42) For every pair of an individual $x$ and a minimal situation $\mathbf{s}_{1}$ such that $x$ is a person in $\mathbf{s}_{1}$ and there is a $y$ such that $y$ is a son in $\mathbf{s}_{1}$ and $x$ has $y$ in $\mathbf{s}_{1}$, there is a situation $\mathbf{S}_{2}$ such that $\mathbf{s}_{1} \leq \mathbf{s}_{2}$ and $x$ thinks-intelligent in $\mathbf{S}_{2}$ the unique $z$ such that $z$ is male in $\mathbf{s}_{1}$.

As (39) instructs us, we construct a comparison LF by replacing the situation semantics quantifier with the corresponding individual-only quantifier. We look for DPs covalued with the trace of the QP, but in this case there are none: kare does not qualify, in contrast to the previous example, since in (42) $x$ and "the unique 
$z$ such that $z$ is male in $\mathbf{s}_{1}$ " (for each $\mathbf{s}_{1}$ ) are not the same, as discussed above. The only change in the comparison LF, then, is the change of the quantifier to the individual-only version. Now kare has a covarying interpretation in the donkey anaphora example (41); but it cannot have such an interpretation in the comparison LF, since there are no situation variables being bound and it does not contain any bindable individual variables. So the truth conditions of the comparison LF are not the same as those of the LF being evaluated, and by (39) the LF being evaluated, with the situation semantics quantifier, is grammatical. This is the correct result, of course.

We see, then, that there is clear support for Modest Situation Semantics as against its less restrained cousin.

\section{Conclusion}

Normal quantifiers like every sometimes quantify over situations. But they are sometimes prevented from doing so. Quantification over situations is more costly than quantification just over individuals and is only resorted to when there is a special need for it. In particular, quantification over situations is subject to the demands of Modest Situation Semantics and the principle of Economy in Quantification (39).

Since (39) is an economy condition on semantic operations, we see that there is further evidence for taking economy conditions to be active in syntax and semantics, as claimed in much work of the past decade.

At the same time, we have seen (in Section 4.4) a novel argument against DRT, lending support to the assumption underlying this paper, that donkey anaphora and related phenomena are to be analyzed by means of situation semantics and some variant of the E-type analysis.

\section{Endnotes}

* For valuable comments on this material I am grateful to Kai von Fintel, Danny Fox, Irene Heim and Shigeru Miyagawa (at MIT), to Chris Barker, Daniel Büring, Jim Higginbotham, Polly Jacobson, Tanya Reinhart, Barry Schein and Karina Wilkinson (at SALT XI), and to two anonymous SALT reviewers. Special thanks to Ken Hiraiwa, Shinichiro Ishihara, Shigeru Miyagawa, Shogo Suzuki and an anonymous FAJL 3 reviewer for giving me Japanese judgments and helping me construct examples.

${ }^{1}$ I follow Heim 1990 in believing that DRT was an unnecessary innovation, in that the pre-existing E-type analysis could have been fixed up in such a way as to (largely) circumvent the objections levelled against it at the time. As for actual arguments against DRT, the most powerful, to my mind, is the existence of certain types of sentences involving paycheck pronouns. Consider (i), where the paycheck pronoun is in a different sentence from its intuitive antecedent, and (ii), where yet another sentence intervenes:

(i) John gave his paycheck to his mistress. Most people put it in the bank. 
(ii) John gave his paycheck to his mistress. Such is the sad state of morality in this day and age! But most people, I'm glad to say, put it in the bank.

In limited circumstances, it is even possible to have a paycheck pronoun when there is no linguistic antecedent whatsoever, as Polly Jacobson has pointed out (personal communication) by means of the following example:

(iii) (New Brown faculty member waves paycheck in air and throws interrogative glance at Jacobson.)

Jacobson: Most of us put it in the Brown Employees' Credit Union.

These examples surely cannot be dealt with by the DRT mechanism of unselective binding; nor will the frequently invoked strategy of dynamic binding improve matters. On the other hand, they are easily dealt with by E-type pronouns in one or another manifestation. Some friends of DRT (Chierchia 1992, 1995) acknowledge that E-type pronouns seem necessary to deal with examples like these and advocate a mixed system with both DRT and E-type mechanisms; but in terms of theoretical parsimony this is the worst of all possible worlds. Since some variant of the E-type approach holds out the promise of handling all the relevant data, in stark contrast to DRT, we should pursue this unless absolutely forced to do otherwise. See further Section 4.4 of the present paper.

2 ' $s_{1} \backslash s_{1}$ ' indicates the object language situation variable $s_{1}$ being replaced by the corresponding (bold-faced) metalanguage variable. For other technical details, readers are referred to Kratzer 1989 and Heim 1990.

3 In this LF I use the variant of the E-type analysis proposed in Elbourne 2001, whereby (i) looks like (ii) at LF :

(i) Every man who owns a donkey beats it.

(ii) every man who owns a donkey beats [it donkey]

The pronoun it has the interpretation of a definite article (Postal 1966), and the NP donkey is deleted in the phonology by NP-deletion, which must be obligatory (in English at least) with those definite articles that we call third-person pronouns. Thus in (4) we have [it sage-plant]. (Note that what appears to be NP-deletion is possible in some cases where there is no linguistic antecedent: in the scenario in (iii) in Note 1, Polly Jacobson could felicitously have said, "No, I've not received mine yet." There is evidently more to NP-deletion than just deletion of material under LF-identity.) The Elbourne 2001 system means we can dispense with a separate category of E-type pronouns-E-type anaphora is to be explained solely by the independently motivated mechanisms of NP-deletion and pronouns being interpreted as determiners.

${ }^{4}$ I will not here investigate the possibility of obtaining the relevant reading for (12) by telescoping, largely because I do not know how telescoping works. See Poesio and Zucchi 1992 for a good introduction to this obscure subject.

5 Sentences in which kare would be bound by a wh-phrase are generally also bad. Hoji (1991) reports that straightforward sentences like 'Who said that Mary hit kare?' are ungrammatical on the reading where kare is bound by who. Interestingly, he reports that these sentences improve markedly when the restrictor on the 
wh-phrase is made to denote smaller and smaller sets: 'Which writer said that Mary hit kare?' is better than 'Who said that Mary hit kare?', and 'Which Nobel Prizewinning writer said that Mary hit kare?' is pretty much fine. I do not have an explanation for this effect. (But neither, I hasten to add, does anyone else. In particular, Hoji's own account makes no semantic sense, since he says that the pronoun in these cases can be 'coreferential' with the wh-phrase.) I speculate that the narrowing of the domain might somehow give an independent motivation for quantification over situations, which would make the relevant sentences grammatical according to the theory I give below.

${ }^{6}$ One could also suggest that there is competition between kare/kanozyo and pro, in that kare and kanozyo are not possible when the null pronoun is possible. But this would predict that (22b) was bad, given the possibility of (22c). See Noguchi's article (1997: 774) for another argument against this hypothesis.

${ }^{7}$ Although it is not essential for the current argument, it may be interesting to note at this juncture that even this, which is a demonstrative that is sometimes claimed to be unbindable, can in fact be bound if one takes the trouble to construct an example in which its proximal semantics is not inappropriate. (i) seems to work pretty well.

(i) Mary talked to no senator without declaring that this was the one who would co-sponsor her bill.

It was suggested to me at SALT XI that if kare is a demonstrative then perhaps the distal/proximal aspect to its semantics might explain its inability to be bound. But this does not explain the contrasts attested: for example, there is no difference between the relationship that holds between John and himself in (22a), "John thinks that he's intelligent", and that which holds between each male person and himself in (23a), "Everyone thinks he's intelligent." But (22a) is good (in the relevant dialect) and $(23 a)$ is bad.

${ }^{8}$ I do not mean to imply that the predicates in tiisai kare and so on actually are non-restrictive relative clauses. They could just be similar uses of adjectives. Irene Heim (personal communication) alerts me to the possible parallel of English expressions like poor me, poor John.

9 Actually things are not quite this simple, since these pronouns are also subject to constraints based on social standing. Noguchi (1997: 778) reports that one does not use them to refer to young children or to adults of higher social status. I abstract away from this here. We must also suppose that these expressions are like ordinary pronouns, and unlike some other definite descriptions, in that they are not subject to Condition $\mathrm{C}$ of the binding theory. This poses no problems, if only because no-one knows why anything should be subject to Condition $\mathrm{C}$ of the binding theory.

${ }^{10}$ Is an index combined with a pronoun by Merge (or whatever we call the normal operation that takes two lexical items and conjoins them in the syntax)? If not, what does the job? If so, why do people not care about type compatibility between the items, as they do in all other cases of Merge? Is an index a lexical item of the normal kind? If so then we are owed an explicit account of its semantic type. If not, what is it? For my own view on these matters, see Elbourne forthcoming. 
11 But see Heim 1993 for a system which requires this.

12 The approach sketched here is reminiscent of that suggested to deal with 'bishop sentences' by Heim (1990: 157-8). I will not here attempt to see whether or not the two come to the same thing. I would like to record, though, that I believe that Heim probably is too harsh towards her solution in her 1990 article. More work needs to be done on this.

${ }^{13}$ Some have objected to (39) on the grounds that it involves comparing derivations. I find these objections odd, since I take the work of Reinhart and Fox cited in this paragraph to indicate that language often works this way. I suspect that the root of the unease is a worry about how this principle would be implemented in accounts of production and processing. There are two possible responses here. Reinhart (personal communication) says that rules or principles which involve comparing derivations should be associated with increased processing difficulty or other psycholinguistic effects indicative of inherent complexity, just as her Rule I was shown to be put into effect by children later, developmentally speaking, than Conditions A and B (Grodzinsky and Reinhart 1993); the comparison of derivations actually happens in real time processing and production, then. The other possible response is the Chomskyan one: as theoretical linguists, our job is not, in the first instance, to construct models of processing and production, but rather to produce explicit algorithms that will correctly pair sound and meaning; these can be expected to form the basis of models of processing and production, but not necessarily without changes and the addition of other principles and heuristics. The choice between these two responses is actually an empirical matter: if psycholinguistic effects of the sort Reinhart would predict come to light, all very well and good; if not, we simply conclude that the implementation of the principle in processing and production is not straightforward. I do not feel it is unjustified, then, to present a principle whose implementation in processing and production models is for the moment obscure.

\section{References}

Aoun, Joseph, and Norbert Hornstein (1992). Bound and referential pronouns. In C.-T. James Huang and Robert May (eds.), Logical Structure and Linguistic Structure, Dordrecht: Kluwer. 1-23.

Berman, Stephen (1987). Situation-based semantics for adverbs of quantification. In J. Blevins and A. Vainika (eds.), University of Massachusetts Occasional Papers 12, University of Massachusetts, Amherst.

Chierchia, Gennaro (1992). Anaphora and dynamic binding. Linguistics and Philosophy 15: 111-183.

Chierchia, Gennaro (1995). Dynamics of Meaning. Anaphora, Presupposition, and the Theory of Grammar. Chicago: University of Chicago Press.

Cooper, Robin (1979). The interpretation of pronouns. In F. Heny and H. Schnelle (eds.), Syntax and Semantics 10: Selections from the Third Gröningen Round 
Table. 61-122. New York: Academic Press.

van Eijck, Jan, and Hans Kamp (1997). Representing discourse in context. In J. van Benthem and A. ter Meulen (eds.), Handbook of Logic and Language. 179-237. Amsterdam and Cambridge, Mass.: Elsevier and MIT Press.

Elbourne, Paul (2001). E-type pronouns as definite articles. In R. Billerey and B. D. Lillehaugen (eds.), WCCFL 19: Proceedings of the 19th West Coast Conference on Formal Linguistics. 83-96. Somerville, MA: Cascadilla Press.

Elbourne, Paul (forthcoming). On the semantics of pronouns and definite articles. In K. Megerdoomian and L.A. Bar-el (eds.), WCCFL 20: Proceedings of the 20th West Coast Conference on Formal Linguistics. Somerville, MA: Cascadilla Press.

von Fintel, Kai (1994). Restrictions on Quantifier Domains. Doctoral dissertation, University of Massachusetts at Amherst.

Fox, Danny (2000). Economy and Semantic Interpretation. Cambridge, Mass.: MIT Press.

Grodzinsky, Yosef, and Tanya Reinhart (1993). The innateness of binding and coreference. Linguistic Inquiry 24: 69-101.

Heim, Irene (1990). E-type pronouns and donkey anaphora. Linguistics and Philosophy 13: 137-177.

Heim, Irene (1993). Anaphora and semantic interpretation: a reinterpretation of Reinhart's approach. University of Tübingen Seminar für Sprachwissenschaft working paper series (SfS-Report-07-93).

Heim, Irene and Angelika Kratzer (1998). Semantics in Generative Grammar. Oxford: Blackwell.

Hoji, Hajime (1991). Kare. In Carol Georgopoulos and Robert Ishihara (eds.), Interdisciplinary Approaches to Language. Essays in Honor of S.-Y. Kuroda. 287-304. Dordrecht: Kluwer.

Huang, C.-T. James (1991). Remarks on the status of the null subject. In Robert Freidin (ed.), Principles and Parameters in Comparative Grammar, Cambridge, Mass.: MIT Press. 56-76.

Katada, Fusa (1991). The LF representation of anaphors. Linguistic Inquiry 22: 287-313.

Kratzer, Angelika (1989). An investigation of the lumps of thought. Linguistics and Philosophy 12: 607-653.

Montalbetti, Mario (1984). After Binding: On the Interpretation of Pronouns. PhD thesis, MIT.

Noguchi, Tohru (1997). Two types of pronouns and variable binding. Language 73: 770-97. 
Poesio, Massimo and Alessandro Zucchi (1992). On telescoping. In Chris Barker and David Dowty (eds.), SALT II. Proceedings from the Second Conference on Semantics and Linguistic Theory, Columbus, Ohio: Ohio State University, Department of Linguistics.

Postal, Paul (1966). On so-called 'pronouns' in English. In F. Dinneen (ed.), 19th Monograph on Languages and Linguistics. 201-24. Washington, D.C.: Georgetown University Press.

Reinhart, Tanya (1983). Anaphora and Semantic Interpretation. London: Croom Helm.

Reinhart, Tanya (1997). Strategies of anaphora resolution. UiL OTS Working Paper TL97-007.

Ruys, Eddy (1993). The Scope of Indefinites. Utrecht: OTS Dissertation Series. 